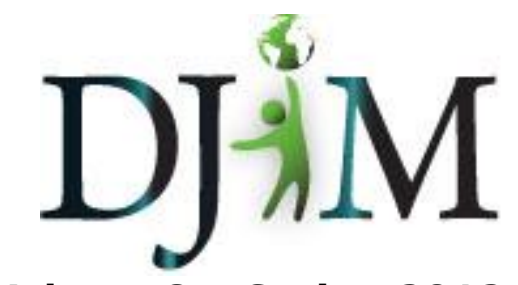

Volume 8 - Spring 2012 djim.management.dal.ca

\title{
Taking The Game Out Of Gamification
}

\begin{abstract}
Gamification purports that the main appeal of video games are game mechanics. Gamification asserts that these mechanics, which include points, badges, levels, etc., can be excised from video games and used to motivate people to perform tasks outside the realm of traditional video games. This paper challenges these claims by arguing that the core of video games is valuable content, not game mechanics. It illustrates how game mechanics are not exclusive to video games and are used only to enhance the content naturally found in games. It further explores how gamification uses mechanics to limit the amount of valuable content provided to players while at the same time gathering valuable personal information from players.
\end{abstract}

\footnotetext{
About the Author(s): Alan Chorney is an MLIS candidate, May 2012, at Dalhousie University. He graduated from the University of Winnipeg with Bachelor of Arts in English where he focused on creative writing. He was twice published in the creative writing journal Juice. This paper was originally developed for INFO 5500: Information in Society.
} 


\section{Introduction}

Panem et circenses. Bread and circuses. Feed the public, entertain the public, and then one should have no problem controlling the public. Gamification falls into the latter category. Like a modern day soothsayer, proponents of gamification claim adding game mechanics to reality can "tackle real dilemmas and improve real lives" (McGonigal, 2011, p. 29). The reality is that gamification is another corporate buzzword thrown around in hopes of making a quick buck. This paper will expose the false claim that gamification purports to be a solution to all of the world's problems through the use of gamification mechanics alone. I will argue that gamificaiton mechanics are not actually core to video games, and as such, excising these mechanics only serves to remove valuable content from video games. Furthermore, the use of these mechanics cannot change human behavior and that outside of properly constructed content game mechanics only serve as a means to take advantage of people by replacing valuable content with corporate propaganda while hoodwinking players into freely parting with personal information.

\section{The Difference Between Game Mechanics and Game Content}

It is important to make a clear distinction between the content of a video game and the mechanics of a video game. The content of a video game is the story, information, and/or experience that is provided by playing a video game. The value in video game content is similar to that of any work of art: a shared experience that can be reflected upon.

Gamification takes valuable content and replaces it with rhetoric and advertising, or valueless content.

Game mechanics are tools used by game designers to add a structure that complements and enhances the content of a video game. These mechanics often take the form of a virtual reward system which can include: points, badges, levels, virtual currencies, etc. It is important to note that the use of game mechanics does not necessarily make the product a video game.

To help make this distinction clear it may help to use the analogy of film. A director can use different shots, cuts, and special effects to affect the viewer, but the end result is not always a movie. It may, in fact, be an advertisement. The identity of the film is directly tied to the content of the film, not the mechanics of the film.

\section{The History of Game Mechanics}

In order to understand the foundational concepts of gamification it is best to examine where it purports to originate and where it draws its influences. McGonigal (2011) believes that games as an historical force can be traced to the ancient Greek Herodotus who wrote of an ancient 
king who used games to distract his citizens from a famine. She views this escape from reality as a helpful distraction and claims that this parallel illustrates how video games can be used to make life livable in hard times. Furthermore she makes a jump in logic to state that through gamification mechanics the force that allows one to be distracted from one's problems can be shifted towards solving the world's problems. The issue with McGonigal's claims is that they require a logical stretch. If games are to solve problems then they must address problems. Avoiding problems can be a powerful tool, and in the right circumstances it may even be a useful tool, but it does not necessarily follow that people can use the power of what distracts them to solve their problems. It is important to note how even in some of the earliest known recordings of human history the power of games as a means of distraction was recognized.

The interest in gamification comes not from a long noble lineage of games leading up to a eureka moment in which forward thinkers recognized the world-changing potential of game mechanics. Instead, video games have recently broken into the mainstream in such a way that players have reached a critical mass that marketers want to exploit. Gamification entrepreneurs will say they are using "techniques that game designers [have] used for years to motivate behavior - points, badges, levels, high score tables and virtual goods" (Paharia, 2011b, para.1). The truth is that these techniques are not core characteristics of video games, nor are they exclusive to video game design. In reality, gamification strips games of their essential characteristic: content, and replaces it with a brand.

Though techniques such as points and high score tables have been used in video games, an examination of video games throughout history can illustrate how good video game designers have allowed such devices to fade into the background of games in favour of content. One of the most famous video game characters of all time, Mario (who was called Jumpman at the time), made his debut in 1981 in the classic arcade game Donkey Kong. The goal of the game is to move Mario from the bottom of the screen to the top in order to rescue a princess who has been kidnapped by a giant gorilla named Donkey Kong. Donkey Kong is trying to impede the process by throwing barrels and placing other obstacles in the path of Mario. Mario gets points for avoiding obstacles and rescuing the princess. Once rescued the princess is promptly stolen again and taken to the top of another screen. This process can be repeated ad infinitum with no real end to the game. When Mario dies, if his running point total was high enough, it gets placed on the high-score board of the arcade machine along with the players initials. The points and high-score board used within the game created a game community. As the arcade machine was located in a public space, every new player could, upon viewing the high-score table, see the initials of the players who were most successful at repeatedly saving the princess. It is important to note that to be placed on the leader board the player had to actually play the game by overcoming obstacles, and that content existed underneath the point/high-score structure. 
In 1985 Super Mario Bros. was released on the Nintendo Entertainment System (NES) home video game console. The goal of this game was for Mario to once again rescue his princess, this time from a villainous lizard monster named Bowser. Mario traversed the virtual world known as the Mushroom Kingdom defeating monsters along the way. While the player received points for defeating these monsters and a tally of this score was kept at the top left hand of the screen, this score was in reality inconsequential. Due to the fact that early console games were located in the home there was no way to create a community based around a high score as access to each console was limited. Furthermore, early consoles had no means of saving any sort of progress. This meant that upon turning off the console any high score data was immediately erased. It is also worth noting that Super Mario Bros. did not contain other so-called core mechanics such as badges or virtual goods. While Super Mario Bros. did contain levels they should not be considered ranks (as they are traditionally thought of in gamification), instead they should be considered more like chapter numbers used to separate sections of a book. Completing a level in a Mario title simply means moving on to the next section of the game. The lack of gamification mechanics used in Super Mario Bros. demonstrates that people will play video games in spite of these mechanics not because of them. The reason people found Super Mario Bros. engaging was because of content. Every fourth level Mario encountered a castle in which he battled through and eventually had an encounter with his nemesis Bowser. Up until the last castle, upon defeating Bowser, Mario would have an interaction with a character named Toad who would repeat the now iconic words "Thank you Mario! But our Princess is in another castle!" (Nintendo, 1985). For players of video games the plot is akin to that of a novel or a movie -- the protagonist is faced with an obstacle which they must overcome.

In 1990 the fourth game in the Super Mario Bros. franchise was released. It was entitled Super Mario World. By this point, technology was present in home consoles that allowed users to save games. While the point system was still present in Super Mario World, the game did not make use of the save feature to save high scores. The feature was instead used to save the players progress through the game, much like placing a bookmark in a book. While it would certainly have been possible for designers to have both the progress and the high score saved, designers choose to ignore the latter, again illustrating its lack of importance as a core part of the game. The use of the word "world" in the title illustrates a conscientious choice on the part of the designers to create an ever improving environment while relegating gamification mechanics to the background. Super Mario World abandons the term "level" to define each section of gameplay and instead names each section of the game. Furthermore, many of the gameplay sections have multiple exits which places the idea of exploration at the forefront of what games can accomplish. While there are only minimal game changes in terms of the use of gameification mechanics between Super Mario Bros. and Super Mario World, the focus on content shifts dramatically. Super Mario World features a much more vibrant world than its predecessors complete, with a wider range of characters and a deeper storyline. This focus 
on content development illustrates that gamification mechanics were not the main focus of game developers, but rather they wanted to create an immersive content filled world.

The last Mario game I will discuss is 1996s Super Mario 64. In this game the designers finally abandon the point system that up until this point had been serving no useful purpose. This game is also significant in that it was the first game in the series to adopt a three dimensional environment to explore. In doing so, the game abandoned any sort of level system in favour of an open world in the form of a castle which the players were free to explore at their leisure. This was also a game in which the creators experimented with the use of badges as a game mechanic. Within the castle were a series of rooms. Each room could only be opened when Mario had obtained a set number of badges (in this case stars). Stars could be obtained by completing various tasks within the castle, thus allowing the player to open more doors, and offering access to more tasks and thus more stars. While these stars are indeed an example of the use of badges within a video game, they are not a core mechanic. Insteadbadges in this game are used to enhance the experience of the content of the game. Much like filmmakers use techniques such as cutting away from a scene early to limit the amount of information the viewer has in regard to the plot of a movie, the badge system in Super Mario 64 is used to limit the amount of content the player has access to throughout the game. Hence, game designers do use gamification mechanics not as core elements, but rather as tools to help shape the content provided.

However, the Super Mario Bros. series is not representative of all video games t. Super Mario Bros. offers content via narrative, much like a novel, and exploration, much like looking at a painting. Another means by which video games can offer content is through puzzle solving. The most popular game of this type is Tetris in which the player must re-arrange falling blocks to create lines across the screen. When a line is completed it disappears and the player is rewarded with points. As the player clears more lines the blocks start to move faster and thereby increase the challenge. The speed by which blocks increase is labeled by the term level. Again, in the Tetris scenario the game mechanics are not necessary. Score and level need not be present for Tetris to function as a game, although they do serve a purpose in that they allow players to gauge their ability. Many puzzle type games, depending on the type of puzzles being solved, abstain from using gamification mechanics. Take for example a jigsaw puzzle, it is similar to Tetris in that different shapes must be placed together in the proper manner, yet a jigsaw puzzle provides a puzzle solving experience without gamification mechanics.

Many video games do use gamification mechanics in a variety of capacities. The point is that video games do not need to use gamification mechanics to be successful, rather they should be treated as techniques that game designers can implement to amplify the style of content which games provide. One of the tenets of good storytelling is to show, not tell. To the video 
game, gamification mechanics are the tell. Good game designers know this. In a recent article predicting the future of video games in the next ten years Nathan Grayson (2011) predicts there will be, "less telling ('Critical hit! 34234!') and more showing (That Super Mutant's skull is, er, no longer in its face." The core of games are not gamification mechanics but, "the operational parts of the games that produce an experience of interest, enlightenment, terror, fascination, hope, or any number of other sensations" (Bogost, May 3, 2011, p. 2).

The mechanics of video games exist and have existed outside of video games for quite some time. Points and high score tables exist in sports where extensive stat tracking is common place. Levels of achievement occur in schools and other places of learning, some examples include: swimming levels, piano levels, reading levels, and skating levels. Badges are tokens of achievement that can be anything from a sticker for successfully using the potty to a gold medal for winning the $100 \mathrm{~m}$ dash at the Olympics. Even the idea of virtual goods has existed for a long time: money itself is a form of virtual worth that has been around for so long that people forget there is no inherent value in physical money. All of these gamification mechanics are motivators that exist outside of video games.

\section{The Push for Gamification}

Gamification as a way to describe game mechanics is a new and divisive term. Its first documented use occurred in 2008, but it didn't achieve widespread adoption until the second half of 2010 (Deterding, Khaled, Nackle, \& Dixon, 2011, p. 1). The newness of this term suggests that the way gamification elements are used as a whole outside of the context of video games is also new; however, as I have explained, this is not the case. The question then becomes why does the push for gamification exist now, especially if the core mechanics pre-date video games? The answer lays in the need for marketers to jump on the hype that has grown around video games, an area which until recently had been a niche market.

World of Warcraft boasts a significant player base of 10.3 million players (Cifaldi, 2011). Beyond a large user base it has a loyal user base that has stayed with the brand since its launch in 2004. It is an example of a content driven game that uses many gamification mechanics. The size and endurance of this game has allowed World of Warcraft to enter the mainstream. Due to the amount of money involved, revenues of up to 1.25 billion dollars per year, its success has not gone unnoticed by the business community (Takahashi, 2011, para. 2). Given the amount of money involved it is no surprise that anything having to do with games is seen as big business. As lan Bogost (2011, Aug. 9) of The Atlantic puts it:

The rhetorical power of the word "gamification" is enormous, and it does precisely what bullshitters want: it takes games--a mysterious, magical, powerful medium that has 
captured the attention of millions of people--and it makes them accessible in the context of contemporary business (para. 6).

In World of Warcraft players are placed in a virtual fantasy world filled with Non Player Characters (NPCs) which serve as content providers. They offer the players quests which serve as goals. These are essentially stories which the player interacts with either alone or in social groups with other players. This valuable content is key to the users of World of Warcraft and other such similar games. Sebastian Deterding who studies the motivational effects of games at the Hamburg University is quoted as saying "I enjoy a video game because I beat the boss monster, not because beating the boss monster gives me 10,000 points" (Campbell, 2011 , p. 39). The problem with such content is that it is expensive to produce. To maintain a virtual world costs the makers of World of Warcraft an estimated 50 million dollars a year (Plunkett, 2008, para.1).

The high cost of creating valuable content for video games is off-putting to marketers of gamification for two reasons. First, 50 million dollars a year to create and maintain content is a large sum of money. Second, as Rajat Paharia (2011a), founder of the gamification company Bunchball says: "making good game is not easy, or everyone would do it." It is much easier, according to Paharia (2011a), to take the content a company already has and build gamification techniques around it to engage the user. The ideal example of this would be a system of gamification techniques where no valuable content was provided, and yet the user was engaged.

Examples of gamification techniques (as they are essentially only motivational techniques) being used without valuable content are not without precedence. One such example, by which feedback and reward engage players without providing valuable content, is slot machines which use the powerful system of random payouts. In the gamification industry, the epitome of gamification exists in a product called Farmville. Farmville is classified by many as a social game.

Whether or not Farmville and other similar products can even be considered games is up for debate. Earlier, I mentioned how video games can provide content in the form of a narrative or puzzles that can keep a player engaged. Farmville offers no such content. In Farmville the player is automatically given a farm and seeds to plant a crop. Crops are always successful and the players can collect money from the crops to buy new crops, farm equipment, and land with which they can expand their farm. In his article Who Killed Videogames? (A Ghost Story) Tim Rogers (2011) snidely likens modern video games to nineties little league baseball in which everyone "gets an identical trophy at the end of the season, even if their pitcher never threw a ball across the plate, even if no bat held by any player on their team ever touched a baseball with that bat" (chap. 1). 
Farmville and other social games give players the illusion of playing a game. Much of the content in traditional video games comes from obstacles placed in the path of the player. Much like in a movie or book the player, who can be associated with the protagonist, draws meaning from these obstacles. In traditional video games this meaning is compounded by the fact that failure is a real and often frequent occurrence. Players of social games forgo this meaning, as no matter how poorly they play "no punishments are given" (Hou, 2011).

Farmville is essentially a virtual shopping environment. Throughout the game the player is given the opportunity to view the farms of high level players who have accrued a large amount of virtual goods. The gamification system in Farmville is such that at the beginning the player is rewarded liberally and often giving the player the illusion that he/she will never have to spend money and that he/she too can have a wealth of virtual goods for free. As the gamification system progresses so to does the frequency of rewards. Eventually the player quits or spends money to buy virtual goods. As one frustrated blogger puts it: "EVERYONE who has reached a high level in Farmville has pulled out their credit card at some point. When you reach a slow point and there is hardly any action occurring like it used to, you trick yourself into paying money for Farm Cash" (Pixie, 2011, para. 1).

Of course the debate over the validity of social games as actual games isn't surprising. Farmville was never designed to provide any real core game mechanics. The goal of Farmville is to make money for its creators. When leaders in the gamification industry such as Gabe Zichermann (2010), Chair of the Gamification Workshops and Summit, and Rajat Paharia (2010), founder of the gamification company Bunchball give lectures about gamification they always cite Farmville as a prime example of gamification done correctly.

\section{The Ineffectiveness of Gamification at Changing Behaviour}

An interesting dynamic emerges when one considers the stated goals of these gamification leaders versus how players actually interact with their games. Gabe Zichermann claims that anything is possible with gamification: "anything can be fun ... we can make government fun. We can make getting fit fun" (Zicherman, 2010). Statements like these purport that gamification has the ability to change people's behaviour and that gamification mechanics can engage people in politics and fitness programs. If you look at Farmville, however, its main goal of procuring funds for its owners is only successful eight percent of the time. (Zicherman, 2011). From a standpoint of the effectiveness of using gamification to change player behaviour this is a terrible statistic. However, from a business perspective, if those eight percent can support the remaining $92 \%$ of players while still providing a profit for the makers of Farmville, then the game is successful. To put this in perspective, if the goal of Farmville was to get people to lose weight or to vote, then only eight percent of the players would actually achieve that task. According to the L.A. Times Zynga, the makers of Farmville, is a company 
worth 3 billion dollars and the cost to produce a game such as Farmville is at most threehundred thousand dollars (Pham, 2010). This means that social games like Farmville that focus on game mechanics are much more profitable to produce and operate versus content driven games such as World of Warcraft.

The idea gamification mechanics do not help to change player behaviour is also supported by research. In a paper recently published in Japan, a game called Ecolsland was used as a case study to examine the effects of gamification. The goal of Ecolsland was to motivate users to decrease their carbon dioxide emissions. The game implemented such gamification mechanics as: a virtual currency, achievements, and immediate feedback. The paper concluded that "if users do not have an environmentally friendly mind and have no interests of saving energy at first place, they will not use Ecolsland no matter wether[sic] there is game mechanics in the system" (Yefeng, Alexandrova \& Najima, 2011, p. 6). The report also suggested that users who were already interested in the core service provided were less influenced by gamification mechanics (Yefeng et al., 2011). The conclusions of this paper support the idea that gamification mechanics alone cannot influence the minds of game players.

Research into so-called social games such as Farmville also concludes that they are played to, "relax, escape from stress, and avoid responsibilities." (Hou, 2011, p.13). Hou (2011) goes on to say, "challenge and competition have been documented as the most popular reasons for playing video games. But neither was a significant motive for playing social games" (p. 13). This suggests that players of these social games have a different set of motivations than those of traditional games. This is in stark contrast to the views of Jane McGonigal (2011) who maintains that the drive of video gamers can be harnessed to bring change to the world. It seems instead that the casual nature of gamification decreases player motivation.

\section{Gamification as Rhetoric}

Traditional video games seek to engage and enlighten players through valuable content. In much the same way as a novel allows its readers to ponder the words written within, video games allow the player to think about the scenarios andinteract with the alternate reality presented in the game. City planning games, such as SimCity, allow the player to interact with and consider urban planning (Lobo, 2010). A game such as BioShock allows the players to consider Ayn Rand's philosophy of objectivism as they explore a dystopian wasteland ("Objectivism," 2010). It is the valuable content in these games that allows for the potential of critical thought and discourse.

Gamified environments remove the value from the content provided. Gamified environments pacify the player in an attempt to get them to go through the mechanical motions of game 
mechanics. When the objective of producers is to glean money from users, the objective of gamification becomes clear. However, when companies such as Warner Brothers set up gamified environments such as InsiderRewards, the motivation becomes somewhat murky. Such gamified environments are set up knowing that the gamification itself will not generate revenue directly in the same manner as a social game such as Farmville.

The obvious advantage to gamification for companies such as Warner Brothers is advertising, but it goes beyond that. By creating a gamified environment, companies can create a world where they have complete control over the information within that world. The information in a gamified world is controlled in three facets: First, the content. This is much like traditional advertising where the advertiser gets to choose the message put out into the world. Second is the content generated by the user. The limits and uses of the environment are determined by the gamification mechanics which are controlled by the company. Third is membership. The company can control access to the environment and this access often comes at the cost personal information.

Philip Man (2011) writes of the gamified world:

Gamification is the latest enticement of the modern landlord to profit from its citizen's livelihood. Game mechanics are implemented, supplying an enslaving substitute for the demise of meaning. Social media companies host the modern tavern, the sandbox, the walled garden, where its users play and produce value (p. 11).

The value that Man writes of is not a tangible sort. No goods are produced. Instead, he is referring to information. From the moment players enters a gamified environment they become of value to the corporation. It is already well known that social networking sites like Facebook collect personal information and this personal information is valuable as it allows for personalized advertising. Many social games such as Farmville operate through Facebook. By playing such games, users are not only giving up valuable information by interacting with the game, they are also giving access to the information contained on their Facebook profile. For gamification environments outside of Facebook, the information is acquired directly at registration. To even begin to use the Warner Brothers' InsiderRewards program the players must give up their first and last names, email address, date of birth, country of residence, and their postal or zip code.

The amount of information obtained only increases as the player enters the gamified environment. Out of necessity, the sign-up page of an environment might act as a barrier, people are forced to \voluntarily give up information in order to participate. Once a member, this information collecting becomes much more subtle. Gamification mechanics lull the user into a false sense of security while "Every click, every photo and every comment or status a 
user gives to the website it contributes to creating value" (Man, 2011, p. 6). In making a pitch about the benefits of gamification to companies Rajat Paharia puts player action in the following terms: "You've raised your hand and said you're interested in this kind of content and now they can market to you with absolute specificity" (2011a).

Participants are willing to partake in this environment because they believe they are getting some sort of value in return. To the players, playing the game is worth having every single mouse click tracked because in return they get virtual goods and rewards. The trouble is that this value can never be extracted by the user. Gabe Zichermann (2011) likens it to a one way valve where consumers can put time and money in but never take anything out.

Gamification environments put companies in a situation where they have absolute control of the information within their environment and they purposely and subtly try to convince the players that it is in their own best interest, because what the gamifed environment offers is the illusion of a reward. Gabe Zichermann's (2011) view on the future of information is as follows:

We've been trying--following this web design holy grail of finding, you know, the most straightforward, cleanest way of presenting information or data. I actually think the tide is turning from a consumer standpoint. I don't think that's the main metric consumers are looking for at all. I think the main metric they are looking for is fun and engagement. And increasingly that will be their number one choice factor in deciding what wins.

In the world of gamification, the role of information is clear. Clear, that is, if you are the content provider. The information you receive from your customers is personal, accurate, and retrieved first hand. If you are the player, however, the situation is reversed. Gamifiers will offer you the world and instead give you fun and engagement. Pacified by gamification techniques, the only world offered to players is one that is clandestinely regimented by content providers. Regarding the future of our world, Man (2011) states: "Society seems to be headed to the digital medieval city where value is created for the corporations while its citizens are playing games and kept happy" (p. 11). It seems then, that in the digital age gamification becomes our circus. Under the guise of gamification players unknowingly give up valuable personal information in exchange for a cloudy game-like experience.

\section{Conclusion}

Games and their mechanics have existed long before video games. It is important to recognize that although these mechanics can be powerful tools and motivators they cannot be used to change the world, as proponents of gamification proclaim. Gamification techniques, as the study of Ecolsland shows, cannot be used to significantly alter human behavior. They can, 
however, as in the case of Farmville or Warner Brothers' InsiderRewards be used to generate revenue, advertise, or gather personal information.

Gamification is a response to the rise in popularity of video games. With this rise in popularity those in the gamification industry have tried to ride the coat tales of this success by swapping out valuable content for rhetoric and advertising. It is important for people to recognize the capabilities and limits of game mechanics and to realize that what gamification professes is different than what it can actually offer. 


\section{References}

Bogost, I. (2011, May 3). Persuasive games: Exploitationware. Gamasutra. Retrieved from http://www.gamasutra.com/view/feature/6366/persuasive games exploitationware.php

Bogost, I. (2011, August 9). Gamification is bullshit. The Atlantic. Retrieved from http://www.theatlantic.com/technology/archive/2011/08/gamification-is-bullshit/243338/

Campbell, M. (2011). The audacious plan to make the world into a game. The New Scientist, 209(2794). http://dx.doi.org/10.1016/S0262-4079(11)60049-3

Cifaldi, F. (2011, November 8). World of warcraft loses another 800k subs in three months. Gamasutra. Retrieved from http://www.gamasutra.com/view/news/38460/World of Warcraft Loses Another $800 \mathrm{~K}$ Subs In Three Months.php

Deterding, S., Khaled, R., Nackle, L. E., \& Dixon, D. (2011). Gamification: Toward a definition. Retrieved from http://hci.usask.ca/uploads/219-02-Deterding,-Khaled,-Nacke,-Dixon.pdf

Grayson, N. (2011, December 7). Gaming mainstays that'll be gone in ten years. IGN UK. Retrieved from http://uk.games.ign.com/articles/121/1214152p1.html

Hou, J. (2011). Uses and gratifications of social games: Blending social networking and game play. First Monday 16(7). Retrieved from http://firstmonday.org/htbin/cgiwrap/bin/ojs/index.php/fm/article/view/3517/3020

Lobo, D. G., (2004). A city is not a toy: How simcity plays with urbanism. The Next American City: Cities \& Technology 6 . Retrieved from http://americancity.org/

Man, P. (2011). Playing the real life: The ludification of social ties in social media. Media. Retrieved from http://www.philipman.net/wp-content/uploads/2011/03/NMT FinalDraft Man1.pdf

McGonigal, J. (2011). Reality is broken: Why games make us better and how they can change the world. New York: Penguin.

Nintendo. (1985). Super Mario Bros. [Video game software]. America: Nintendo.

Objectivism in bioshock. (2008, Febuary 15). Kotaku. Retrieved from http://kotaku.com/354717/no-gods-or-kings-objectivism-in-bioshock 
Paharia, R. (2010). Driving user behavior with game dynamics. Stanford University.

Retrieved from

http://www.youtube.com/watch?v=MCfUFpZUk6s

Paharia, R. (2011a). Saatchi s perspective: Rajat paharia, founder - bunchball [video].

Retrieved from

http://www.youtube.com/watch?v=rtOoNR83Thw

Paharia, R. (2011b, July 27). The rise of gamification. Adotas. Retrieved from http://www.adotas.com/2011/07/the-rise-of-gamification/

Pixie, Y. (2010, March 22). 10 reasons why I left farmville [Weblog]. Retrieved from http://blogcritics.org/gaming/article/10-reasons-why-i-left-farmville/

Pham, A. (2010, Febuary 19). How social games make money: Lessons from farmville. Retrieved from http://latimesblogs.latimes.com/entertainmentnewsbuzz/2010/02/how-social-gamesmake-money-lessons-from-farmville.html

Plunkett, L. (2008, September 16). How much has wow cost blizzard since 2004. Kotaku. Retrieved from http://kotaku.com/5050300/how-much-has-wow-cost-blizzard-since-2004

Rogers, T. (2011, September 22). Who killed videogames? (a ghost story). Insert Credit. Retrieved from http://insertcredit.com/2011/09/22/who-killed-videogames-a-ghost-story/

Takahshi, D. (2011, September 1). Updated: Activision blizzard could make $\$ 1.25$ billion in additional revenue in next three years. GamesBeat. Retrieved from http://venturebeat.com/2011/09/01/activision-blizzard-could-make-more-than-1-25-billionin-profits-from-new-business-models/

Yefeng, L., Alexandrova, T., \& Najima, T. (2011). Gamifying intelligent environments. International ACM Workshop on Ubiquitous Meta User Interfaces. Retrieved from http://www.dcl.info.waseda.ac.jp/ yefeng/yefeng/pubs/2011/ubimui11 yefeng.pdf

Zichermann, G. (2010). Fun is the future: Mastering gamification [Video]. Google Tech Talk. Retrieved from http://www.youtube.com/watch?v=601gNVeaE4g

Zichermann, G. (2011). Gamification - the new loyalty [Video]. Copenhagen: Gamification Co. Retrieved from http://vimeo.com/25714530 